\title{
Mental models: a basic concept for human factors design in infection prevention
}

\author{
Sax, H ; Clack, L
}

\begin{abstract}
Much of the effort devoted to promoting better hand hygiene is based on the belief that poor hand hygiene reflects poor motivation. We argue, however, that automatic unconscious behaviour driven by 'mental models' is an important contributor to what actually happens. Mental models are concepts of reality-imaginary, often blurred, and sometimes unstable. Human beings use them to reduce mental load and free up capacity in the conscious mind to focus on deliberate activities. They are pragmatic solutions to the complexity of life. Knowledge of such mental processes helps healthcare designers and clinicians overcome barriers to behavioural change. This article reviews the concept of mental models and considers how it can be used to improve hand hygiene and patient safety.
\end{abstract}

DOI: https://doi.org/10.1016/j.jhin.2014.12.008

Posted at the Zurich Open Repository and Archive, University of Zurich

ZORA URL: https://doi.org/10.5167/uzh-107600

Journal Article

Accepted Version

Originally published at:

Sax, H; Clack, L (2015). Mental models: a basic concept for human factors design in infection prevention. Journal of Hospital Infection, 89(4):335-339.

DOI: https://doi.org/10.1016/j.jhin.2014.12.008 
H. Sax et al.

\section{Mental models: a basic concept for human factors design in infection prevention}

H. Sax , L. Clack

HAL 14, Division of Infectious Diseases and Infection Control, University Hospital Zurich, Raemistrasse 100, 8091 Zurich, Switzerland

*Corresponding author. Tel.: +41 44-255-57-30.

E-mail address: hugo.sax@usz.ch (H. Sax).

\section{SUMMARY}

Much of the effort devoted to promoting better hand hygiene is based on the belief that poor hand hygiene reflects poor motivation. We argue, however, that automatic unconscious behaviour driven by 'mental models' is an important contributor to what actually happens. Mental models are concepts of reality - imaginary, often blurred, and sometimes unstable. Human beings use them to reduce mental load and free up capacity in the conscious mind to focus on deliberate activities. They are pragmatic solutions to the complexity of life. Knowledge of such mental processes helps healthcare designers and clinicians overcome barriers to behavioural change. This article reviews the concept of mental models and considers how it can be used to improve hand hygiene and patient safety.

Keywords:

Behaviour change

Human factors engineering

Infection prevention and control

Mental models

\section{Once upon a time ...}

... a senior infection control physician set out on a covert mission to observe hand hygiene in an intensive care unit. He selected a room with three patient bays, the outer two of which were occupied by intubated, sedated patients. It was around 3 o'clock on a late summer afternoon and a gentle sunlight was filtering through the blinds of the large windows. There was none of the usual hectic activity in the room, only the soothing sound of the two ventilators going in and out of sync. A young nurse who was sitting at the computer terminal by one patient seemed also to be responsible for a second patient, whose bed was beneath the window. The curtains between patient bays were half open so she could see both patients from where she was sitting. The physician introduced himself as an infection control physician interested in the physical environment of the intensive care unit. He asked the nurse about the process of cleaning the bays between patient admissions, how cleaners knew what 
to do and if there was always enough time for the required procedure. The nurse replied with her views and the conversation turned to her very recent participation in simulation-based hand hygiene training a few days earlier. She reviewed the training enthusiastically, saying that she found the 'my five moments of hand hygiene' concept plausible and helpful. ${ }^{1}$ During this exchange, an alarm on the second patient's monitor went off. The nurse went over, silenced the alarm on the monitor while establishing what was wrong, adjusted the ventilator tube, and checked the infusion pumps and the infusion hubs. This happened three times during the twenty-minute conversation. To the astonishment of the observing physician, she completely ignored all the hand hygiene indications both before and after touching the patient or his surroundings, resulting in a compliance rate of $0 \%$ for six hand hygiene opportunities. After a while, a technician arrived to attend to the continuous haemofiltration machine of the second patient, equally ignoring most of the hand hygiene opportunities while wearing the same pair of gloves for the whole care procedure (overall compliance, 25\%). The physician ended the conversation with the nurse and, in line with his covert observation protocol, left the intensive care unit without mentioning her hand hygiene lapses. This is a true story of events some years ago at a major tertiary care hospital in Switzerland. It suggests that we need to change our thinking about hand hygiene performance and infection prevention strategies.

When assessing the verbalized attitudes and beliefs of this nurse against the theory of planned behaviour, she would certainly score high on intention to act. $^{2}$ She expressed positive beliefs about the outcome of the activity, and she would probably also have responded positively if questioned about social norms. ${ }^{3}$ Moreover, the behaviour in question was not obstructed by any of the frequently cited barriers to hand hygiene - since time pressure did not appear to be an issue, and hand-rub dispensers were abundant and conveniently located around each bed. ${ }^{4}$ Why, then, did she fail to act as she intended?

\section{The conscious mind's bias of being in control}

The mismatch between the expressed intentions and the actual behaviour of the young nurse is just one pointer to the now widely accepted belief that certain processes that determine behaviour are unconscious. The attempt to better understand these processes has led to an operational definition of unconsciousness as 'a lack of awareness regarding the influences or effects of a triggering stimulus. ${ }^{5,6}$ The psychologist and Nobel Prize winner in economics, Daniel Kahneman, has shown elegantly how our unconscious minds control our judgement and behaviour - and that we are 'hardwired' to ignore this fact. An evolutionary explanation for our brains working this way is easy to accept if one considers the advantages, for survival in a hostile environment, of quick and intuitive actions. Furthermore, deliberate 
thinking requires effort and draws on limited mental resources. Relying on intuition to make sense of complex situations quickly and so remain in action may therefore be seen as an 'economic' necessity.

\section{The theory of mental models}

It is postulated that human beings understand the world by unconsciously forming working 'mental models' of the things they observe. ${ }^{7,8}$ Such models are internal images, gathered through experience and observations to collectively form an internal representation of the individual's understanding the world around her. These 'small-scale models' of external reality are then unconsciously projected on to subsequent experiences, serving as a guide to interpret new observations and make predictions. ${ }^{9}$ It is worth noting that whereas mental models form the basis of how we understand and communicate with the world, they are by no means complete, nor necessarily accurate, representations of reality. ${ }^{8}$ They are pragmatic solutions for dealing with complexity. A popular example is the London Underground map, an iconic representation of the real network of tunnels and stations. The map is useful to get from station A to station B, but not at all geographically accurate. Adding information to a model does not necessarily make the model more useful. Indeed, the simplistic nature of mental models may be the key to their utility, enabling faster intuitive decisions. Similarly, it is the simplicity of the London Underground map (in not portraying real distances in scale) that makes it so is easily readable.

We are largely unaware of our constant recourse to mental models. Cues in the external environment serve as triggers, unconsciously activating relevant mental models. Predictions are then generated based on these mental models, which provide a shortcut, allowing consequent actions to be executed quickly, without conscious deliberation each time a similar set of inputs is encountered. This feature of mental models is what makes them simultaneously economically efficient and yet highly susceptible to error.

Since they rely heavily on past experiences, mental models may be activated in response to environmental stimuli that appear similar, yet are fundamentally different from previously experienced situations - resulting in false predictions and suboptimal behaviour. For example, in a study of home thermostat use, Kempton revealed two commonly held mental models among Michigan residents about how thermostats function. ${ }^{10}$ One particular mental model predicts that setting the thermostat to a higher temperature increases the amount of heat released. This mode of operation is learned through previous experience with gas burners and water valves, where increasing the setting increases the rate of flow. It is, however, an inaccurate mental model when applied to thermostats, which actually monitor current temperature and adapt flow of heat in order to maintain the desired setting. This inaccurate 
mental model causes many people to operate thermostats ineffectively, resulting in wasted energy and high costs.

Moreover, two people faced with the same situation may hold different mental models. If left unresolved, this variation may present challenges for team coordination, as different individuals respond differently to the same cues. Contradictory mental models may even exist within the same individual. One can easily imagine how such a system can lead to misguided reasoning and behaviour. That is why the concept of mental models is useful to those interested in dealing with human error.

There are two opportunities for avoiding erroneous perception and behaviour based on mental models: human factors design and individual 'mindfulness'. Here we elaborate only on the former.

\section{Mental models at the core of human factors design in healthcare}

Human factors design is the scientific discipline that seeks to optimize the interactions among humans and other system elements, particularly in work environments, for the benefit of both well-being and overall system performance (International Ergonomics Society, 2000; http://www.iea.cc/whats/). Over the past decade, human factors design has been increasingly recognized as a tool for optimizing healthcare, particularly in the field of patient safety and infection prevention. ${ }^{11-18}$ The concept of mental models is an important design tool for human factors engineers.

Regarding infection prevention and control, we propose two approaches: first, providing opportunities for healthcare workers to optimize, through experience, their mental models regarding infection prevention and control; second, designing the workplace so that it aligns with existing mental models and supports the safe behaviour of healthcare workers and other staff.

\section{Inducing helpful mental models}

Due to the ever-adaptive nature of mental models, they are continuously being shaped by new experiences and new observations. This has implications in the field of infection control as it relates to the way that healthcare workers' mental models shape their intuitive perception of infection risks. One difficulty inherent to the field of infection prevention lies in the fact that pathogens are invisible to the naked eye. This characteristic makes it impossible to visualize where infection risks lie. It is therefore a real challenge to introduce such invisible risks into the mental models of care providers. With hand disinfection, one way of achieving this is by using fluorescent hand-rub solutions. An exemplary study found that fluorescent coverage of the hands following disinfection with the fluorescent hand-rub solution correlated well with the effectiveness of hand disinfection, as measured by microbiological cultures. ${ }^{19}$ 
The invisible nature of pathogens also makes it more difficult to improve hand hygiene in settings where hands may not be visibly soiled, yet still need disinfection. When preparing the Swiss Hand Hygiene Campaign in 2005, it became apparent that simple and unambiguous rules were needed to specify precisely when hand hygiene was required during patient care. A human factors design approach resulted in the development of the 'my five moments for hand hygiene' concept. ${ }^{1,20}$ This aimed to establish a standardized model of hand hygiene that could be applied to multiple care settings, thereby reducing ambiguity and introducing a unified mental model for healthcare workers.

Another challenge inherent to infection prevention is the delayed or often non-existent feedback following unsafe behaviour. Such unsafe behaviour does not always result in adverse outcomes, and, when it does, the delay between the action or inaction and the adverse event precludes association with the behaviour itself. Mental models allow individuals to make inferences about the outcome of future events based on their previous experiences with similar events. Missing or delayed feedback following unsafe behaviour promotes faulty mental models that view unsafe behaviour as harmless, because negative outcomes are not observed. Systems with missing or delayed feedback loops are notoriously difficult to control. Routine audits followed by timely, individualized feedback as well as reporting of healthcareassociated infectious events allow healthcare workers to 'see' the connection between behaviour and outcome. A recent review of best practice in infection control found that regular audits followed by timely feedback were effective in improving compliance with control measures and ultimately reducing healthcare-associated infections. ${ }^{21-26}$ Heuristics, which can be described as mental shortcuts or rules of thumb, draw on existing mental models in order to enable rapid judgements. Notably, the affect heuristic, also described as 'risk as feelings', and the availability heuristic, in which individuals judge the likelihood of an event by how easy it is to think of examples, play an important role in how individuals perceive and act on risks. ${ }^{27,28}$ When considering the role that such cognitive biases play in risk perception, feedback and reporting should be designed in order to keep adverse events fresh in the minds of everyone involved.

\section{Designing to benefit from existing mental models}

If designers could access the internal representations that guide the actions of individuals, they might be able to design systems that support optimal human behaviour. Such interventions could be more effective than teaching or guideline provision alone. Support might be provided through subliminal pathways, such as the introduction of cues that trigger automatic behaviour, or through conscious pathways, by signage and visual cues. Evolution has made us highly sensitive to our present environment. Unconscious processes are 
constantly taking note of local conditions and automatically adjusting behaviour accordingly.

This phenomenon has been termed 'priming', in which certain cues automatically activate relevant mental models and elicit relevant behaviour. ${ }^{5}$ One channel for behavioural priming is through the olfactory system, as odour has been shown to influence behaviour. Specifically, a fresh lemon fragrance, which invokes mental models of hygiene and cleanliness, has been demonstrated as having a positive effect on hand hygiene behaviour in a simulated environment. $^{29}$

A classical human factors engineering approach is to establish a work environment that is designed to make safe behaviours intuitive and to prevent errors of omission by providing visual cues as reminders. Nevo et al. found that purposefully selecting the locations of alcohol-based hand-rub dispensers and increasing their visibility through blinking lights improved adherence with simple hand hygiene rules. ${ }^{30}$ Interestingly, the activation of social norms among healthcare workers by placing a sign on the door warning that the room was under surveillance had an even greater effect on hand hygiene. ${ }^{30}$

When designing to support mental models, one must remember that they are often incomplete, inaccurate, and inconsistent between individuals. Mental models that differ between individuals may present a source of misunderstanding and poor team performance. Where hand hygiene is concerned, having incongruent perception of patient zones that define hand hygiene indications may lead to unintentional transmission of pathogens (Figure 1A). Such incongruities may easily be solved by means of simple design solutions (Figure 1B).

\section{Conclusions}

The intensive care nurse portrayed at the beginning of this article operated in an environment that provided no cues for risk perception. Her conscious mental capacity was presumably occupied by her conversation with the infection control physician. In consequence, she probably executed the repeated to-and-fro between the two patients habitually, almost on auto-pilot, hand hygiene not yet being integrated into her mental model of this activity. This story can be seen as a 'black swan event', a single observation that comes as a surprise and radically changes the way we see facts. ${ }^{31}$ It might explain why attempts to improve hand hygiene practice by persuasion, motivation, and communication of rules usually fall short of the desired effect. The story might hold the key to better understanding of what underlies missed hand hygiene actions during complex healthcare activities and so offer an opportunity for human factors design. It has certainly changed the authors' own mental models of hand hygiene behaviour, raising the hope that similar stories can change the mental models and behaviour of others, too.

\section{Conflict of interest statement}


None declared.

\section{Funding source}

The production of this manuscript was partially funded by the Swiss National Science Foundation (Project 32003B_149474).

\section{References}

1. Sax H, Allegranzi B, Uckay I, Larson E, Boyce J, Pittet D. 'My five moments for hand hygiene': a user-centred design approach to understand, train, monitor and report hand hygiene. J Hosp Infect 2007;67:9-21.

2. Ajzen I. The theory of planned behavior. Organ Behav Hum Decis Process 1991;50:179211.

3. Schneider J, Moromisato D, Zemetra B, et al. Hand hygiene adherence is influenced by the behavior of role models. Pediatr Crit Care Med 2009;10:360-363.

4. Pittet D. Improving compliance with hand hygiene in hospitals. Infect Control Hosp Epidemiol 2000;21:381-386.

5. Bargh JA, Morsella E. The unconscious mind. Perspect Psychol Sci 2008;3:73-79.

6. Bargh JA, Schwader KL, Hailey SE, Dyer RL, Boothby EJ. Automaticity in social-cognitive processes. Trends Cogn Sci 2012;16:593-605.

7. Johnson-Laird PN. Mental models. Cambridge, MA: Harvard University Press; 1986.

8. Sterman JD. Learning from evidence in a complex world. Am J Public Health 2006;96:505-514.

9. Craik KJW. The nature of explanation. Cambridge, MA: Cambridge University Press; 1943.

10. Kempton W. Two theories of home heat control. Cogn Sci 1986;10:75-90.

11. Kohn LT, Corrigan JM, Donaldson MS, editors. To err is human: building a safer health system. Washington, DC: National Academy Press; 2000.

12. Gurses AP, Ozok AA, Pronovost PJ. Time to accelerate integration of human factors and ergonomics in patient safety. BMJ Qual Saf 2012;21:347-351.

13. Gosbee J. Human factors engineering and patient safety. Qual Saf Health Care 2002;11:352-354.

14. Anderson J, Gosbee LL, Bessesen M, Williams L. Using human factors engineering to improve the effectiveness of infection prevention and control. Crit Care Med 2010;38:S269-281.

15. Gurses AP, Pronovost PJ. Physical environment design for improving patient safety. HERD 2011;5:3-5.

16. Storr J, Wigglesworth N, Kilpatrick C. Integrating human factors with infection 
prevention and control. 2013. http://socialwelfare.bl.uk/subject-areas/services-

activity/health-

services/healthfoundation/1532972013_integrating_human_factors_with_infection_preve ntion_and_control.pdf (accessed 24 Jun 2013).

17. Clack L, Kuster SP, Giger H, Giuliani F, Sax H. Low-hanging fruit for human factors design in infection prevention - still too high to reach? Am J Infect Control 2014;42:679_ 681.

18. Clack L, Schmutz J, Manser T, Sax H. Infectious risk moments: a novel, human factorsinformed approach to infection prevention. Infect Control Hosp Epidemiol 2014;35:1051-1055.

19. Hautemanière A, Diguio N, Daval MC, Hunter PR, Hartemann P. Short-term assessment of training of medical students in the use of alcohol-based hand rub using fluorescentlabeled hand rub and skin hydration measurements. Am J Infect Control 2009;37:338340 .

20. Sax H, Allegranzi B, Chraïti M-N, Boyce J, Larson E, Pittet D. The World Health Organization hand hygiene observation method. Am J Infect Control 2009;37:827-834.

21. Zingg W, Holmes A, Dettenkofer M, et al. Hospital organization, management and structure in the context of healthcare-associated infection prevention: a systematic review. Lancet Infect Dis. DOI: http://dx.doi.org/10.1016/S1473-3099(14)70854-0 [Epub].

22. Moongtui W, Gauthier DK, Turner JG. Using peer feedback to improve handwashing and glove usage among Thai health care workers. Am J Infect Control 2000;28:365-369.

23. Charrier L, Allochis MC, Cavallo MR, Gregori D, Cavallo F, Zotti CM. Integrated audit as a means to implement unit protocols: a randomized and controlled study. J Eval Clin Pract 2008;14:847-853.

24. Kilbride HW, Wirtschafter DD, Powers RJ, Sheehan MB. Implementation of evidencebased potentially better practices to decrease nosocomial infections. Pediatrics 2003;111:e519-533.

25. Cocanour CS, Peninger M, Domonoske BD, et al. Decreasing ventilator-associated pneumonia in a trauma ICU. J Trauma 2006;61:122-129; discussion 129-130.

26. Yinnon AM, Wiener-Well Y, Jerassy Z, et al. Improving implementation of infection control guidelines to reduce nosocomial infection rates: pioneering the report card. $J$ Hosp Infect 2012;81:169-176.

27. Tversky A, Kahneman D. Availability: a heuristic for judging frequency and probability. Cogn Psychol 1973;5:207-232. 
28. Slovic P, Peters E. Risk perception and affect. Curr Dir Psychol Sci 2006;15:322-325.

29. Birnbach DJ, King D, Vlaev I, Rosen LF, Harvey PD. Impact of environmental olfactory cues on hand hygiene behaviour in a simulated hospital environment: a randomized study. J Hosp Infect 2013;85:79-81.

30. Nevo I, Fitzpatrick M, Thomas R-E, et al. The efficacy of visual cues to improve hand hygiene compliance. Simul Healthcare 2010;5:325-331.

31. Taleb NN. The black swan. New York; Random House; 2010.

Figure 1. Simple design solution to mitigate systems ambiguity. (A) Two incongruent mental models of the patient zone delineation are demonstrated. One healthcare worker (HCW 1; solid line) considers the computer to be outside of the patient zone, whereas the other healthcare worker (HCW 2: dotted line) considers the computer to be inside the patient zone. This ambiguous computer zone represents a transmission hot spot. Arrows represent the inconsistent hand hygiene $(\mathrm{HH})$ indications according to the varying mental models, resulting in cross-transmission to and from the patient. (B) Simple design solution to align mental models of all healthcare workers in the form of a marking on the floor. 
A

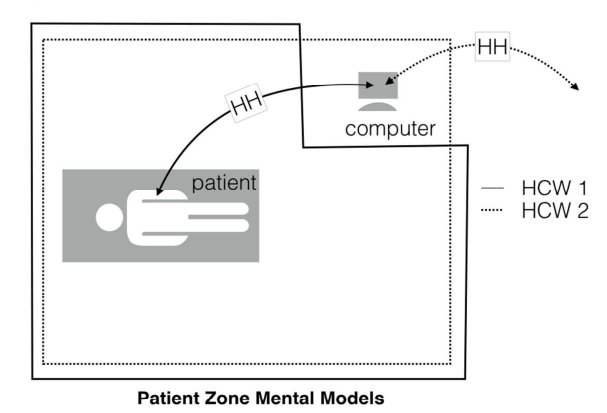

Patient Zone Mental Models

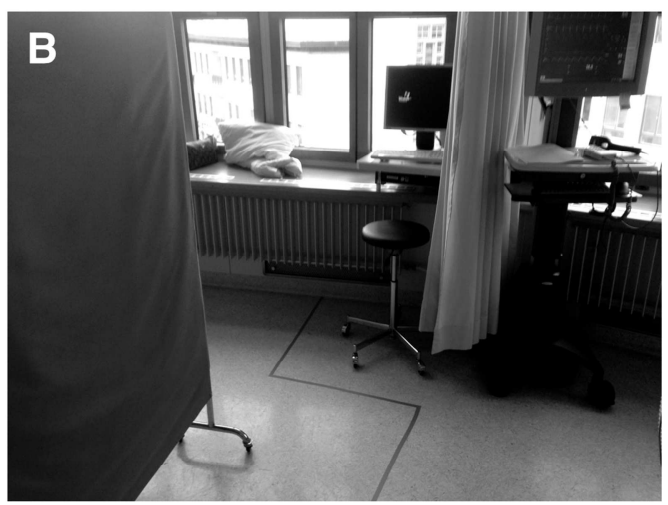

